\section{P-158 PROMOTING BEST PRACTICE IN AN INCLUSIVE WAY}

Caroline Welch, Tracy Levison, Terrileigh Hackett, Val Stangoe. Hospice of St Mary of Furness, Ulverston, Cumbria

\subsection{6/spcare-2021-Hospice.174}

Background To ensure best practice and legal compliance we needed an easy reference handbook detailing the procedures and guidelines for our retail teams that was set out in such a way that anybody, regardless of their role could pick up and independently and efficiently find the solution to any issue or information they need at a glance.

Aims We wanted to create a handbook that was user-friendly by looking at the effect of typographical features on how efficiently the text can be read; typographical features include things like font choice, text size, colour (Horstmann \& Herwig, 2016; Miller, 1956) and contrast.

Methods Jan 2021: Research led by a psychology graduate with special interest in cognitive psychology into legibility and the effect of typographical features. Particular focus was given to needs of individuals over the age of 60 (Bernard, Liao \& Mills, 2001) and those with dyslexia. Jan - March 2021: Formatting of all text in line with research recommendations. May - Jun 2021: Consultation with staff and volunteers for feedback.

Results The feedback we have received so far (examples below) from our staff and volunteers has been extremely positive.

- 'Easy to read because of the coloured boxes. If I see a red box I know I legally need to comply!'

- 'Text is big enough that I can read it without my glasses.'

- 'Easy to digest the information because the important points were highlighted, you could focus, you weren't having to read it worrying you might miss something important! Easy to access certain topics if need to refresh knowledge, check a procedure or train a new volunteer.'

Conclusion Having the correct organisation and layout significantly improves the readability of our handbook. We have a format which can be deployed across all communication to our retail teams to attract the attention of the reader and to improve reading comprehension and memory.

\section{P-159 IMPLEMENTING ORGANISATIONAL CHANGE: A HOSPICE SITE MOVE}

${ }^{1}$ Joanne Kinloch, ${ }^{1}$ Michael Grant, ${ }^{2}$ Anne Hattie. ${ }^{1}$ The University of Strathclyde, Glasgow, UK;

${ }^{2}$ The Prince and Princess of Wales Hospice, Glasgow, UK

\subsection{6/spcare-2021-Hospice.175}

Background An organisational site move can prove challenging to instigate, navigate, motivate and successfully implement (Kotter, 2012; Slosberg, Nejati, Evans, Nanda, 2018). The development of a change management strategy can aid in the success of such endeavours (Slosberg, Nejati, Evans, Nanda, 2018; Periyakoil, 2009). These strategies are often complex, requiring consideration over psychological and structural factors at individual and organisational levels (Holt, Helfrich, Hall, et al., 2010).

Aims To document and interrogate the preparation, execution and outcomes of a change management strategy supporting the transition from an existing site to a new purpose-built hospice facility. To provide and validate a framework for the successful implementation of future transitional projects.

Methods A case study was conducted on a hospice organisational site move. Following an initial literature review, review of project documentation, and site surveys, staff members contributed to the completion of individual interviews and focus group sessions. Transcripts were subjected to thematic analysis in order to identify and code themes and outcomes for comparison to existing data on best practice

Results 49 members of staff across Inpatient, Day and Outpatients Services, Family Support Services, Front of House, Facilities, Management and Administration contributed to the data capture. These data were then cross-referenced to existing change management models. Evidencing that the hospice strategy could be validated against existing theory and supported by the documented outcomes. Ultimately, the change management process was positively received and contributed towards a successful transition.

Conclusion This hospice organisation demonstrated the importance of a holistic strategy for change management. It resulted in the identification and evaluation of the implementation strategy utilised by the hospice organisation, highlighting areas of consideration to guide future projects.

\section{P-160 CONSISTENT VALUES, NEW THINKING, NEW WAYS OF WORKING: WHAT OUR HOSPICE STRATEGY DOES FOR US}

Glen Dewsbury, Emma Johnson. St. Leonard's Hospice, York, UK

\subsection{6/spcare-2021-Hospice. 176}

Background Making sense of the unprecedented degree of complexity in patient need, the health sector and in the communities we serve demands a close focus on strategic thinking and new ways of working to deliver excellent care and service. At St Leonard's Hospice we have implemented a Strategy Balanced Scorecard System in order to help us do this.

Aims To build on our tradition of delivering excellent palliative and end-of-life care to our community through a process of strategic planning and change management, led at every stage by our shared values of excellence, integrity and respect.

Methods Draw on our shared values to meet new challenges. Implement a Strategy Balanced Scorecard System to capture and communicate strategic aims. Deliver the aims through a planned implementation process. Embed project management discipline in the implementation process. Build a process of formal review to support continuous improvement.

Results Though our implementation is at an early stage and has been impacted upon by operational demands arising from the pandemic, we see: a transition from fiduciary to strategic governance at Board level; increasing strategic focus at senior team level; an appetite amongst all managers and staff to revitalise our values by using them as practical decision-making tools. Our next steps are: to build on staff open forums with focussed consultation on our mission, purpose and values; review how information flows in our teams; embed valuesdriven problem-solving across our teams and use the Balanced Scorecard Dashboard to measure to improve continuously. Project management discipline will then support the delivery of our Strategic Aims as 'One Hospice' team. 